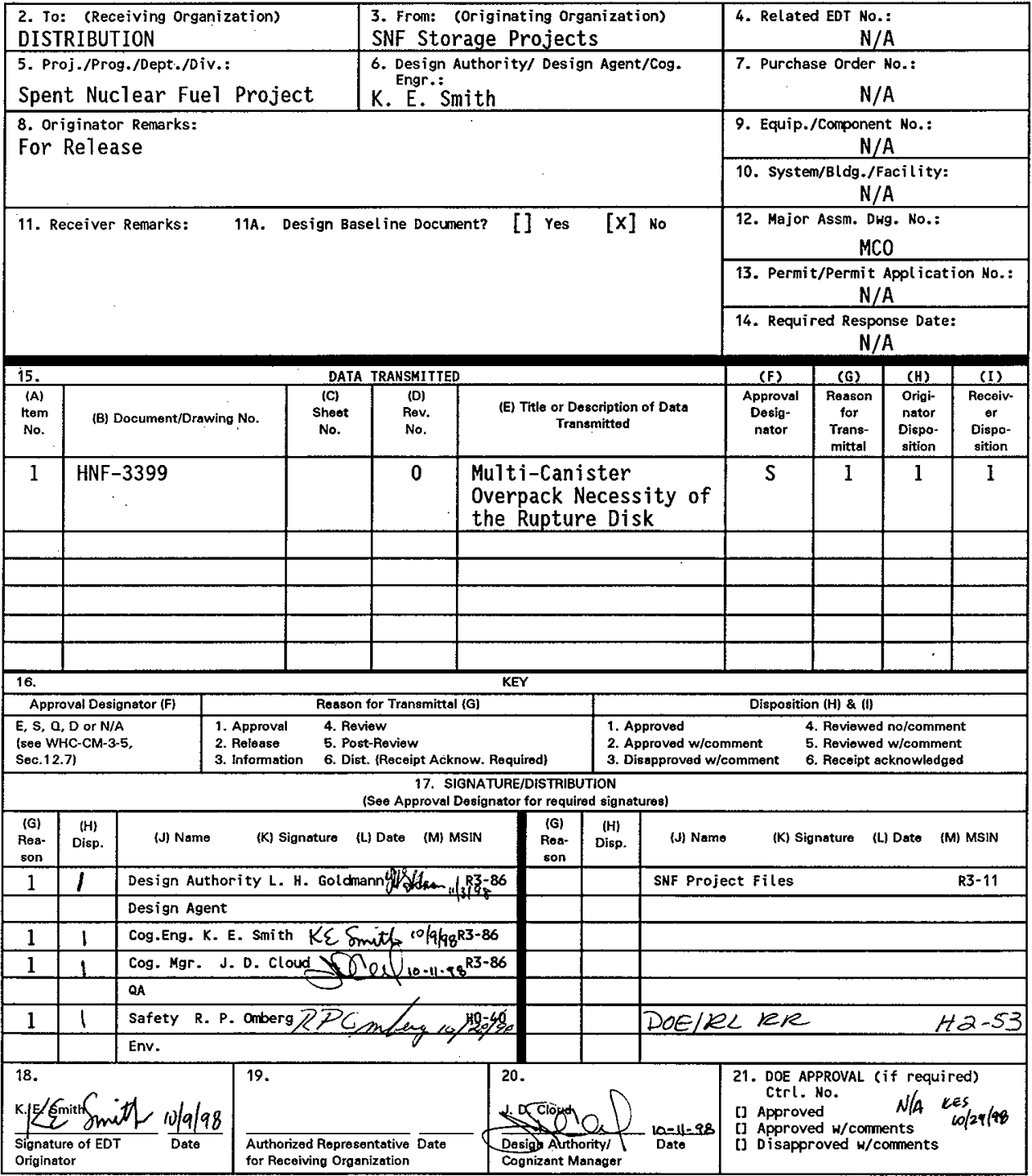

BD-7400-172-2 (05/96) GEF097 


\section{Multi-Canister Overpack Necessity of the Rupture Disk}

\section{K. E. Smith}

DE\&S Hanford, Inc., Richland, WA 99352

U.S. Department of Energy Contract DE-AC06-96RL13200

$\begin{array}{lll}\text { EDT/ECN: } & 625778 & \text { UC: } 600 \\ \text { Org Code: } 2 T 340 & \text { Charge Code: } 105532 / A A 30 \\ \text { B\&R Code: } & \text { EW7040000 } & \text { Total Pages: } 5\end{array}$

Key Words: MCO, Spent Fuel, Pressure Relief, Packaging, Container, Issue, Rupture Disk

Abstract: The Multi-Canister Overpack (MCO) rupture disk precludes the MCO from pressurization above the design limit during transport from the $K$ Basins to the Cold Vacuum Drying (CVD) Facility and prior to connection of the CVD process piping. Removal of the rupture disk from the MCO design would: a) result in unacceptable dose consequences in the event a thermal runaway accident occurred; b) increase residual risk; and c) remove a degree of specificity from the dose calculations. The potential cost savings of removing the rupture disk from the MCO design is offset by the cost of design modifications, changes to hazard analyses and safety analyses, and changes to existing documentation. Retaining the rupture disk mitigates the consequences of MCO overpressurization, and considering the overall economic impacts to the SNF Project, is the most cost effective approach.

IRADEMARK DISCLAIMER. Reference herein to any specific commercial product, process, or service by trade name, trademark, manufacturer, or otherwise, does not necessarily constitute or imply its endorsement, recommendation, or favoring by the Uni ted States Government or any agency thereof or its contractors or subcontractors.

Printed in the United States of America. To abtain copies of this document, contact: Document Control Services, P.O. Box 950, Mailstop H6-08, Richland WA 99352, Phone (509) 372-2420; Fax (509) 376-4989.
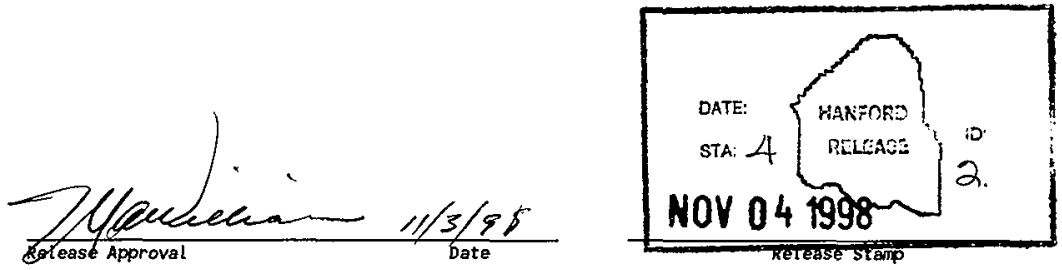

Approved for Public Release 
HNF-3399, Rev. 0

Issue Closure Package

Issue: MCO Necessity of the Rupture Disk

Lead:

K. E. Smith

$K \varepsilon$ S mitt $10 / 9 / 90$

MCO Implementation

Manager, DE\&S Hanford

Approvals:

Chief Engineer:

A. M. Segrest DE\&S Hanford

Technical Operations:

J. A. Swanson

Manager

DE\&S Hanford

Construction Projects:

A. R. Hollies

Manager

DE\&S Hanford

Nuclear Safety:

Robert G. Morgan

Manager

DE\&S Hanford

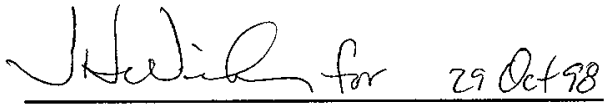

Signature
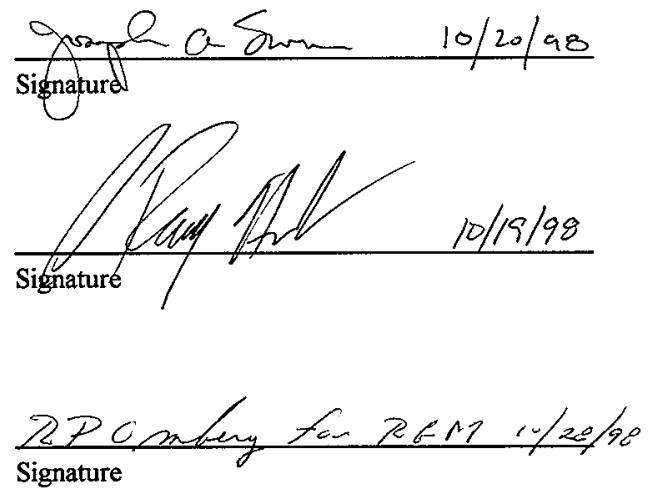

Signature

Hours Holduruon 10/1/98

Signature 
HNF-3399 Rev. 0

\section{MULTI-CANISTER OVERPACK}

\section{NECESSITY OF THE RUPTURE DISK}

\subsection{SUMMARY}

Removal of the rupture disk from the design of the MCO was considered. From a safety perspective, the rupture disk performs two main functions.

- Mitigates consequences of MCO overpressurization and reduces residual risk

- Provides a specific accident initiation point for quantification of accident consequences in the Cold Vacuum Drying Facility (CVDF)

By retaining the rupture disk in the MCO design, perturbations to each of the above functions are avoided. Because pressurization of the $\mathrm{MCO}$ beyond the design pressure of the mechanical closure is a credible event prior to commencement of CVDF processing (e.g. operator fails to open vent path), retention of the rupture disk in the MCO design is necessary to preclude pressurization above the design limit. In addition, removing the rupture disk from the MCO design at this stage of the project would have adverse impacts on both cost and schedule.

\subsection{STATEMENT OF THE ISSUE}

With incorporation of the MCO Sealing Strategy, the rupture disk is no longer required after CVDF processing and during the forty year storage period. An evaluation of the need for the rupture disk up through completion of the CVDF processing is warranted.

\subsection{BASIS FOR CLOSURE}

The safety analysis group has considered the impacts of retaining or deleting the rupture disk from the MCO design. Removal of the rupture disk from the MCO design would: a) result in unacceptable dose consequences in the event a thermal runaway accident occurred; b) increase the residual risk; and c) remove a degree of specificity from the dose calculations. It has also been concluded that removal of the rupture disk does not in any way benefit the safety case. Removal of the rupture disk at this stage of the project would have a disruptive effect with respect to design changes to both the MCO and the CVDF process piping, modification of existing safety analysis, identification and 
definition of specific MCO failure mechanisms, and revision of supporting documentation for the safety basis. Any cost savings that may be realized by removing the rupture disk from the MCO design would be offset by design modifications, changes to hazards analyses and safety analyses, and changes to existing documentation. Removal of the rupture disk offers no increased margin of safety and results in the need for additional analyses and design modifications. Based on the above considerations, the rupture disk should remain in the MCO design.

\subsection{DISCUSSION}

The present design of the MCO includes four (4) ports on the shield plug. Each port permits filtered or screened access to the interior of the MCO. A rupture disk is fitted as part of Port \#4 and is set to actuate when pressure within the MCO reaches 150 psig.

Prior to and during CVDF processing, the most critical time from a safety perspective, the rupture disk is active. Following processing at the CVDF, the port containing the rupture disk is blanked off and is not available for any pressure relief.

Removal of the rupture disk would result in the MCO being without adequate pressure relief capability while at the $\mathrm{K}$ Basins, during transport to $\mathrm{CVDF}$, and prior to connection of the process lines to the MCO at the CVDF. During transport and prior to connection to CVDF equipment, overpressurization of the MCO may result from failure to maintain a vent path. Though unlikely, this event is considered credible.

During processing at the CVDF, the MCO confinement boundary and structural integrity are protected by facility systems. The rupture disk provides a secondary relief path function to relieve pressure in a controlled manner in the event that an MCO would pressurize. The point at which pressure is relieved is important because it is directly proportional to the dose consequences. In addition to providing a quantifiable method for determining the unmitigated dose consequences, the rupture disk port also provides a pathway of sufficient relief capacity for the thermal runaway events. If the rupture disk is removed from the MCO design, the design of the CVDF process piping will need to be modified to establish a quantifiable point at which releases from the MCO begin. This purpose is currently served by the existing $\mathrm{MCO}$ rupture disk. Removal of the rupture disk will involve two design changes; one to remove the rupture disk from the MCO and one to modify the CVDF process piping to accomplish an equivalent function.

The rupture disk is installed as part of the process valve located in Port \#4. In addition to providing overpressure protection, this process valve/rupture disk assembly acts as a backup process port for the cold vacuum drying process in the event Port \#2 or the $\mathrm{MCO}$ internal filters become 
HNF-3399 Rev. 0

inoperational, blinded, or blocked. Even if the rupture disk were not needed from a safety perspective, it is prudent to maintain the capability to process through Port \#4 to address potential operating difficulties.

The potential cost savings to be realized from deletion of the rupture disk is approximately $\$ 200$ per MCO ( $\$ 80 \mathrm{~K}$ for $400 \mathrm{MCOs}$ ). This savings would be offset by design modification costs to the MCO and CVDF subprojects, hardware costs to the CVDF, and significant costs to modify hazards analyses, safety analyses, and other project documentation. A rough order of magnitude estimate for these costs is $\$ 200 \mathrm{~K}$ to $\$ 300 \mathrm{~K}$. Considering the overall economic impacts to the SNF Project, retaining the rupture disk is the most cost effective approach. 


\section{DISTRIBUTION COVERSHEET}

Subject: MCO ISSUE PAPERS PER ATTACHED DISTRIBUTION INDEX

\section{DISTRIBUTION}

Name

W. C. Alaconis

R3-86

G. D. Bazinet

S8-06

J. D. Cloud

R3-86

D. R. Duncan

R3-86

J. R. Frederickson

R3-86

L. J. Garvin

R3-26

L. H. Goldmann

R3-86

A. R. Hollins, Jr.

R3-86

C. R. Hoover

R3-86

J. J. Irwin

R3-86

B. D. Lorenz

R3-26

C. R. Miska

R3-86

R. G. Morgan

R3-26

R. P. Omberg

$\mathrm{HO}-40$

A. M. Segrest

R3-11

R. A. Sexton

R3-86

K. E. Smith

R3-86

J. A. Swenson

R3-11

N. H. Williams

R3-11

Project File

R3-11

w/att

U.S. Department of Energy

C. B. Loftis

S7-41

P. G. Loscoe

S $7-41$

E. D. Sellers

S7-41

J. B. Sullivan

S7-4I

$X$
$X$
$X$
$X$
$X$
$X$
$X$
$X$
$X$
$X$
$X$
$X$
$X$
$X$
$X$
$X$
$X$
$X$
$X$
$X$

$X$
$X$
$X$
$X$ 


\section{DISTRIBUTION INDEX}

The Multi-Canister Overpack Issue papers listed below are being distributed as a package to facilitate future reference and use by SNF Project personnel. The following issue papers are attached:

1. HNF-2876, Oxygen Gettering Issue Closure Package

2. HNF-3265, MCO Number of Shield Plug Ports

3. HNF-3399, MCO Necessity of the Rupture Disk

4. HNF-3267, MCO Dual Pressure Rating

5. HNF-3293, MCO Ultrasonic Examination of Closure Weld

6. HNF-3354, MCO Monitoring Issue Closure Package and HNF-3312, MCO Monitoring Activity Description

7. HNF-3292, MCO Sealing Configuration

8. HNF-3266, MCO Design Pressure Rating

9. HNF-3255, ASME Code Requirements for MCO Design and Fabrication

10. HNF-3398, MCO Inservice Inspection and Maintenance

11. HNF-3420, MCO Internal HEPA Filters

12. HNF-3036, Low Reactive Surface Area Issue Closure Package

13. HNF-3270, MCO Pressure Testing 